\title{
Platelets and atherogenesis: Platelet anti-aggregation activity and endothelial protection from tomatoes (Solanum lycopersicum L.) (Review)
}

\author{
IVÁN PALOMO ${ }^{1,2}$, EDUARDO FUENTES $^{1,2}$, TERESA PADRÓ $^{3}$ and LINA BADIMON ${ }^{3}$ \\ ${ }^{1}$ Department of Clinical Biochemistry and Immunohematology, Faculty of Health Sciences, University of Talca; \\ ${ }^{2}$ Centro de Estudios en Alimentos Procesados (CEAP), Conicyt-Regional, Gore Maule, Talca, Chile; \\ ${ }^{3}$ Cardiovascular Research Center (CSIC-ICCC), Hospital de la Santa Creu i Sant Pau-Instituto de \\ Investigación Biomédica Sant Pau, CiberOBENU, Instituto Carlos III, Barcelona, Spain
}

Received October 26, 2011; Accepted December 19, 2011

DOI: $10.3892 /$ etm.2012.477

\begin{abstract}
In recent years, it has been shown that platelets are not only involved in the arterial thrombotic process, but also that they play an active role in the inflammatory process of atherogenesis from the beginning. The interaction between platelets and endothelial cells occurs in two manners: activated platelets unite with intact endothelial cells, or platelets in resting adhere to activated endothelium. In this context, inhibition of the platelet function (adhesion/aggregation) could contribute to the prevention of atherothrombosis, the leading cause of cardiovascular morbidity. This can be achieved with antiplatelet agents. However, at the public health level, the level of primary prevention, a healthy diet has also been shown to exert beneficial effects. Among those elements of a healthy diet, the consumption of tomatoes (Solanum lycopersicum L.) stands out for its effect on platelet anti-aggregation activity and endothelial protection, which may be beneficial for cardiovascular health. This article briefly discusses the involvement of platelets in atherogenesis and the possible mechanisms of action provided by tomatoes for platelet anti-aggregation activity and endothelial protection.
\end{abstract}

\section{Contents}

1. Introduction

2. Role of platelets in atherogenesis

Correspondence to: Dr Iván Palomo, Department of Clinical Biochemistry and Immunohematology, Faculty of Health Sciences, University of Talca, Mailbox 747, Talca, Chile

E-mail: ipalomo@utalca.cl

Key words: tomatoes, cardiovascular disease, platelet antiaggregation activity, endothelial protection
3. Tomatoes: Platelet anti-aggregation activity and endothelial protection

4. Conclusion

\section{Introduction}

According to the World Health Organization (WHO), cardiovascular disease (CVD) (i.e., acute myocardial infarction, cerebrovascular disease and peripheral arterial thrombosis) is the cause of approximately $30 \%$ of deaths worldwide (1), with a relative increase over time due to the aging of the population (2). The development and progression of CVD lies in the interactive processes of atherosclerotic lesions and thrombus formation, an interaction established primarily by plateletendothelial binding (3).

The activation of vascular endothelium occurs early in the development of atherosclerosis (4), where the inflammatory component, present in all phases of atherosclerosis, is a vascular response to guard against cardiovascular risk factors (i.e., hypertension, diabetes, smoking and obesity) $(5,6)$. This inflammatory process generates a microenvironment characterized by oxidative stress and cell damage (7). The process triggers a loss of endothelial function through a decrease in the bioavailability of nitric oxide (NO) and the physiological mechanisms of cardiovascular protection that are derived from it (8).

The role of platelets in arterial thrombosis is well known (9). When there is a damaged atheromatous plaque, platelets adhere, secrete their contents, and then attach to it (10). This activation causes a redistribution of anionic phospholipids, creating a negatively charged surface (11) which, in addition to the synthesis and expression of tissue factor (12), favors the consecutive formation of protein complexes in coagulation and fibrin and the consolidation of the thrombus (13).

Epidemiological studies have demonstrated the cardiovascular protective role of a healthy diet (14). In this context, the beneficial effects of fruits and vegetables $(F \& V)$ may be related to the bioactive compounds found therein (15), which 
explains the increasing amount of attention in research on phytochemicals in the prevention of CVD (16). In addition to their nutritional value, tomatoes (Solanum lycopersicum L.), fresh or processed, have been found to provide a cardioprotective effect at both the endothelial and platelet levels (17).

This article discusses current knowledge of platelet-endothelial interaction during the development of atherosclerosis, and platelet anti-aggregation activity and the endothelial protective effects from tomatoes.

\section{Role of platelets in atherogenesis}

In the last decade, it has been shown that platelets are not only involved in the inflammatory complications of the atheromatous lesion (18) but are also involved in the initiation and progression of atherosclerotic plaque (19). Accordingly, platelets act as a bridge between the inflammatory processes characteristic of atherosclerosis and thrombosis (20). The interaction of platelets with endothelial cells (ECs) occurs in three forms: activated platelets join with ECs in the normal state; resting platelets adhere to activated ECs; or an interaction can occur between the two types of activated cells (21).

Union of activated platelets to ECs in the normal state. Endothelium in the normal state plays a fundamental role in regulating the hemostatic balance (22) through various mechanisms of antiplatelets, anticoagulants and fibrinolysis, which are regulated by the secretion of NO and prostacyclin (23).

In vitro studies have demonstrated platelet adhesion to ECs in the normal state (24). Platelet adhesion occurs because it is activated in circulation. By contrast, in other in vivo studies, the binding occurs under shear conditions (25). Once activated, platelets may adhere to ECs and promote local vascular inflammation through inflammatory mediators such as the secretion of chemokines (26), which disrupt normal functioning of the endothelium (27). For example, platelets store and express CD40L (inflammatory modulator) on their surface, releasing the protein into the environment once they are activated (28). CD40L also induces the expression and release of metalloproteinases, which degrade extracellular matrix proteins that are exposed to the circulation when damage occurs at the endothelial level (29). In addition to the release of sCD40, IL-1 $\beta$, which promotes increased IL- 6 and IL- 8 and the expression of cell adhesion molecules such as E-selectin, intercellular adhesion molecule-1 (ICAM-1) and vascular cell adhesion molecule-1 (VCAM-1) in the EC $(30,31)$, is also released. This leads to the recruitment of leukocytes to the site from which the injury (i.e., damaged endothelium) originated (32). The leukocyte-platelet interaction causes a wide range of responses in the innate and adaptive immune systems (33), giving the platelet a new function as regulator of the immune system, which contributes to the pathogenesis of an inflammatory response $(34,35)$.

Moreover, animal models have shown a high level of P-selectin expression and endothelial growth factor (VEGF) in atherosclerotic plaques with involvement in the progression of CVD (36). Platelet factor 4 (PF-4), CCL5 (RANTES) and platelet-derived growth factor (PDGF) molecules released from activated platelets cause chemotaxis of monocytes and other leukocytes on the EC, and promote the retention of low density lipoprotein (LDL) and oxidized LDL in the subendo- thelium (37). In patients with CVD, the presence of oxidized LDL promotes the release of neutrophil-peptide 78 (ENA-78), with an increase in chemoattractant capacity (38). It has been shown that RANTES and PF-4 have heterophile actions, and that the latter must undergo structural modifications in order to amplify its effects on monocytes (39). Moreover, the deposit of RANTES on the endothelium is promoted by platelet P-selectin (40). PDGF also stimulates smooth muscle cell proliferation, causing hyperplasia of the intima layer of the arterial wall, thus acting as an amplifier of the inflammatory response (41).

Union of resting platelets with activated ECs. Normally, ECs form neither a non-adherent nor a thrombogenic surface (42). Under physiological conditions this is able to exert important regulatory functions, such as maintaining the balance between procoagulant and anticoagulant factors, vascular tone regulation and control of vascular permeability $(43,44)$. Under normal resting, platelets do not adhere to the endothelium (45). However, several factors can alter this balance, establishing what is known as endothelial dysfunction (46). A dysfunctional endothelium generates a proatherogenic environment characterized by inflammation, proliferation and a prothrombotic state favoring the development of atherosclerosis (47).

Changes in the endothelium can begin at a young age, with slow and progressive developments of atherosclerotic lesions occurring as an individual ages (48). The first evidence of the process is the decrease in NO synthesis (49), causing a decrease in vasodilatory capacity and the establishment of a proinflammatory and prothrombotic state in the endothelium (50). Furthermore, this decrease in NO creates an oxidative environment that eventually oxidizes LDL from the plasma passing the site of endothelial injury, where the presence of lysophosphatidylcholine increases oxidative stress (51), adhesion of monocytes (52) and induces in the EC the expression of adhesion molecules (ICAM-1, VCAM-1, P-selectin, among others) through two signaling pathways: i) lysophosphatidylcholine/nuclear factor $\kappa \mathrm{B}(\mathrm{NF}-\kappa \mathrm{B})$ and ii) lysophosphatidylcholine/receivers coupled $G$ protein 4/adenosine monophosphate (cAMP)/protein kinase A/cAMP response element binding protein $(53,54)$. Endothelial P-selectin allows platelets to roll on the activated endothelium (55), permitting adhesion, activation and platelet aggregation in disturbed areas of the endothelium. This process represents one of the main events in the initiation and development of atherosclerosis (56).

Furthermore, it has been demonstrated that ADAM-15 expressed in activated ECs interacts with the GPIIb/IIIa complex and induces platelet activation (57). ADAM-15 also operates as a metalloproteinase, degrading endothelial matrix proteins (58). The two functions of this molecule could facilitate the instability and rupture of the fibrous cap of atherosclerotic lesions, causing the acceleration of the formation of a platelet thrombus (59).

\section{Tomatoes: platelet anti-aggregation activity and endo- thelial protection}

The report 'Diet, Nutrition and the Prevention of Chronic Diseases', published by the WHO in 2003, outlined the scientific evidence that has been associated with a decreased risk 
of CVD. According to the report, individuals who consume at least $400 \mathrm{~g}$ of $\mathrm{F} \& \mathrm{~V}$ daily were found to have a reduced risk of CVD (60). By consuming 5 servings of F\&V daily there is a $17 \%$ reduction in the risk of CVD (61). Furthermore, the effects of consuming F\&V have been replicated worldwide and are independent of ethnicity or geographical location (62).

Presently, in addition to their recognized high value in vitamins, minerals and dietary fiber, consuming $\mathrm{F} \& \mathrm{~V}$ is associated with phytochemical content $(63,64)$, with specific actions on target functions (65). These effects, in terms of primary prevention, could modify cardiovascular risk without any of the side effects normally associated with the majority of antiplatelet drugs (66).

The antioxidant properties of F\&V are well known (67-69). However, their antithrombotic effects on platelet-endothelial interaction are less known. Preliminary studies have demonstrated the platelet anti-aggregation activity of fruits (red grapes, strawberries, kiwis and pineapples) and vegetables (garlic, onions, green onions, melons and tomatoes) $(70,71)$. Among those beneficial elements mentioned above, the consumption of tomatoes, the fruit of a dicotyledonous plant belonging to the Solanaceae family, is emphasized (72). The possible mechanisms of action of bioactive compounds from tomatoes that have platelet anti-aggregation activity and endothelial protective effects are subsequently discussed $(73,74)$.

Platelet anti-aggregation activity of bioactive compounds from tomatoes. It has been observed that the tomato has platelet antiaggregation activity in vitro and in vivo by inhibiting platelet aggregation induced by ADP and collagen (75-80). This finding has also been confirmed by our research group (71). The various platelet anti-aggregation activity levels observed in different varieties of tomatoes can be explained by the existence of one or more bioactive compounds or different concentrations of the same compound (77). The platelet anti-aggregation activity of aqueous and methanol extracts of tomatoes ('cluster' type) in vitro were similar. Both types of extract showed inhibition of platelet aggregation (30-40\%) at $1 \mathrm{mg} / \mathrm{ml}$ induced by ADP. When collagen was used as agonist, inhibition was lower, whereas the use of arachidonic acid and peptide receptor activator of thrombin showed no inhibitory effect (71).

The experimental results obtained by Fuentes et al indicate that aqueous and methanol extracts resuspended in $0.9 \%$ saline exhibit a $\mathrm{pH}$ of 4.5 ; when resuspended in more acidic (pH 2.0) and basic ( $\mathrm{pH}$ 10.0) suspensions, they maintained their inhibitory activity of maximum platelet aggregation (78). As we know that carotenoids are unstable at $\mathrm{pH}$ extremes, this finding may exclude the possibility that these antioxidant compounds exhibit platelet anti-aggregation activity (82-84). In addition, the platelet anti-aggregation activity is inversely related to tomato ripening and the increase in the concentration of lycopene (77).

In the study by Fuentes et $\mathrm{al}$, aqueous and methanol extracts under various temperatures $\left(22,60\right.$ and $\left.100^{\circ} \mathrm{C}\right)$ maintained their platelet anti-aggregation activity, indicating that the active compounds with platelet anti-aggregation activity present in the two extracts were not affected by heat treatment (78).

These results allow us to identify the tomato as a functional food, with one or more bioactive compounds with acid-base and thermal stability to exert its cardioprotective activity.
This characteristic will benefit future efforts to protect the molecular structure and corresponding platelet anti-aggregation activity of tomato extracts during processing, storage, transport, management and molecular action. This will prove useful in the search for alternative antithrombotic therapy, a field in which most of the drugs used have a high instability in the environment of action (85).

The mechanism of action by which the tomato inhibits platelet aggregation has yet to be elucidated (86). It has been suggested that adenosine and other nucleosides may be responsible for this inhibition, possibly via a mechanism independent of cAMP generation (79) and thromboxanes (cyclooxygenase pathway) (75)

However, there are a wide range of bioactive compounds in tomatoes with platelet anti-aggregation activity, some of which have known bioavailability (flavonoid derivatives), and others whose bioavailability has yet to be identified (87). It is also necessary to determine those anatomical sites of the tomato (skin, pulp, seeds, etc.) in which compounds with platelet anti-aggregation activity are found. Based on the results of our research, the bioactive compounds of tomatoes have thermal and acid-base stability, are devoid of lycopene and have low molecular weight (<1000 Da). Moreover, we hypothesize that bioactive compounds exercise their antiplatelet activity via three platelet receptors: GPVI (collagen agonist) and P2Y1 and P2Y12 (ADP agonist) (71). Further studies of the possible mechanisms of action found in the search strategies of alternative pathways of platelet aggregation inhibition possessed by naturally occurring compounds are required. These studies will allow us to identify their therapeutic range of application (Fig. 1).

Study of intraplatelet signaling pathways. Studies of platelet aggregation with bioactive compounds (88) using ADP or collagen as agonist and subsequent platelet lysate for the Western blot test should examine: i) expression of phospholipase $C \beta$ and ii) expression of phospholipase $C \gamma 2$. The first is the signaling pathway involved in the possible interaction of bioactive compounds with ADP receptor (P2Y1) (89). It is also necessary to study the proteins that are related to this signaling pathway. These proteins include total Akt and phospho-Akt (serine 473/ threonine 308) (90). The latter, expression of phospholipase $\mathrm{C} \gamma 2$, is involved in the interaction of bioactive compounds with the collagen receptor (GPVI) (91). Future studies should examine the bioactive compounds of this signaling pathway: total Erk, phospho-Erk 1/2 (threonine 202/ tyrosine 204, threonine 185/ tyrosine 187), total- JNK, phospho-JNK (threonine 182/tyrosine 185) and total p38 MAPK and phospho-p38 MAPK (threonine 182/tyrosine 182) (92). This approach reveals active and inactive forms of these proteins after they have been treated with bioactive compounds, as well as a potential target of action in the corresponding signaling pathway.

Analysis of cytosolic calcium. If there is a decrease in cytosolic calcium levels when platelet aggregation is inhibited, it signifies that the bioactive compounds are exerting their action through GPVI or P2Y1 receptors (93).

Cytosolic cAMP analysis. An increase in cytosolic calcium level may indicate that the bioactive compounds are inhibiting platelet aggregation through the platelet receptor P2Y12 (94). 


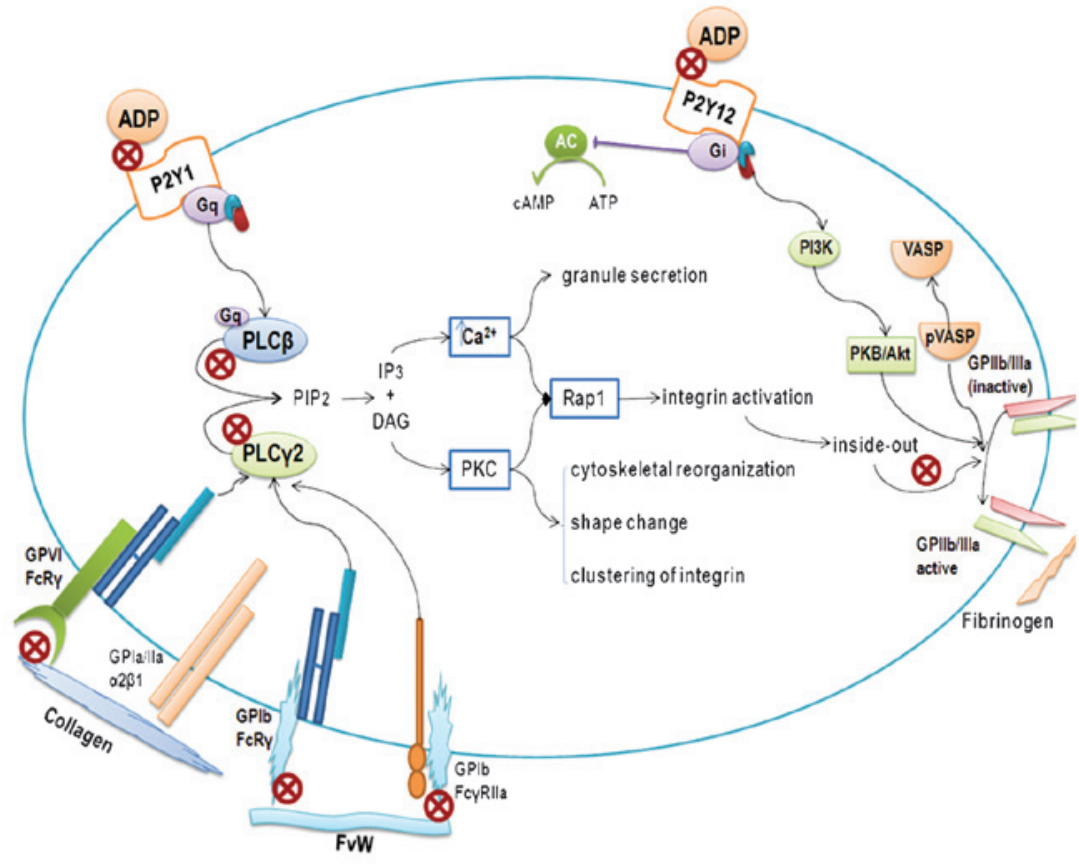

Q indicates inhibition or blockade

Figure 1. Platelet anti-aggregation activity. Schematic diagram showing possible mechanisms of action of bioactive compounds from the tomato in inhibiting platelet aggregation. ADP, adenosine 5'-diphosphate; AC, adenilate cyclase; ATP, adenosine 5'-triphosphate; cAMP, adenosine 3'5'cyclic monophosphate; DAG, dyacil glycerole; FvW, von Willebrand Factor; GP, glycoprotein; Gq and Gi, G protein-coupled receptors; IP3, inositol 1,4,5-trisphosphate; PLC $\beta$, phospholipase C $\beta$; PLCy2, phospholipase Cy2; PIP2, phosphatidylinositol 4, 5-bisphosphate; PKC, protein kinase C; PI3K, phosphoinositide 3-kinase; PKB/ Akt, protein kinase B; P2Y1 and P2Y12, ADP receptors; Rap1, ras-related protein 1; VASP, vasodilator-stimulated phosphoprotein; pVASP, phosphorylatedvasodilator-stimulated phosphoprotein.

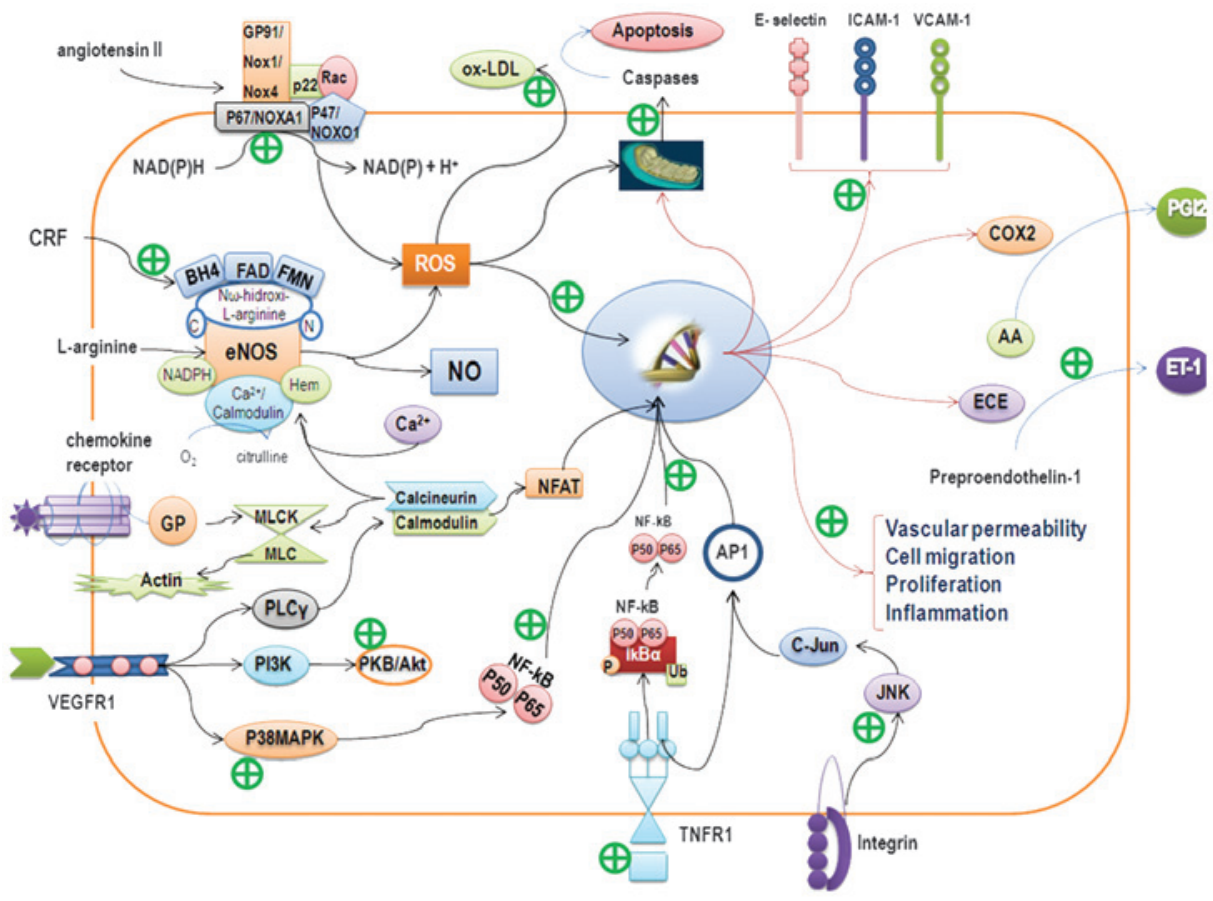

$\bigoplus$ indicates protection against endothelial damage

Figure 2. Endothelial protective mechanism. Schematic diagram showing possible mechanisms of action of bioactive compounds from the tomato in protecting endothelium. AA, arachidonic acid; AP-1, activator protein-1; BH4, tetrahydrobiopterin; COX2, cyclooxygenase 2; CRF, cardiovascular risk factor; ECE, endothelin-converting enzyme; eNOS, endothelial nitric oxide synthase; ET-1, endothelin-1; FAD, flavin adenine dinucleotide; FMN, flavin mononucleotide; ICAM-1, intercellular adhesion molecule 1; IkB $\alpha$, inhibitor of I-k-B- $\alpha$; JNK, c-Jun N-terminal kinase; ox-LDL, oxidized low-density lipoprotein; MLCK/ MLC, myosin light chain kinase-myosin light chain; NADPH, nicotinamide adenine dinucleotide phosphate; NFAT, nuclear factor of activated T-cells; NFkB, nuclear factor $\mathrm{\kappa B}$; NO, nitric oxide; GP, G protein; PGI2, prostacyclin I2; PI3K, phosphoinositide 3-kinase; PLCy, phospholipase Cy; PKB/Akt, protein kinase B; p38MAPK, p38 mitogen-activated protein kinase; ROS, reactive oxygen species; TNFR1, tumor necrosis factor receptor-1; VCAM-1, vascular cell adhesion molecule-1; VEGFR1, vascular endothelial growth factor receptor-1. 
This receptor modulates the inhibition of GPIIb/IIIa through vasodilator-stimulated phosphoprotein (VASP) (95).

Study of platelet adhesion. After incubating platelets with bioactive compounds, they were deposited in fibrinogen or VWF matrices $(96,97)$. A reduced matrix adhesion of fibrinogen (fibrinogen binding capacity) indicates that the bioactive compounds block GPIIb/IIIa-fibrinogen interaction via the amino acid sequence RGD (arginine-glycine-aspartic acid), or inhibit a signaling pathway involved in the expression of GPIIb/IIIa. Thus, complete blockage of the GPIIb/IIIa platelet receptor inhibits aggregation from forming a platelet thrombus (98). Bioactive compounds may affect the interaction of platelet (GPIb/IX/V) with endothelium (vWF) (24).

Protective activity from tomatoes on the endothelial function of bioactive compounds. It has been observed that aqueous and methanol extracts of tomatoes exhibit antioxidant activity in vitro $(67,99)$. Carotenoids ( $\beta$-carotene, lycopene, zeaxanthin, lutein and canxantina) and vitamins $\mathrm{C}$ and $\mathrm{E}$, when they are found in tomatoes, possess endothelium-protective activity. These molecules have three main methods of action (Fig. 2): i) they cause antioxidant activity by protecting LDL and increasing resistance to oxidation (100); ii) in humans, it has been reported that supplementation with lycopene reduces oxidative damage to DNA and other markers of oxidative stress (101); and iii) lycopene has been found to inhibit the expression of adhesion molecules in ECs (102).

Cystine-knot miniproteins from tomato with low concentrations and low toxicity have active anti-angiogenic effects through their inhibition of Erk phosphorylation and do not affect the normal viability and proliferation of ECs (103). They have a similar function to carotenoids, which prevent the phosphorylation of Akt, p38 MAPK and JNK and are sensitive to reactive oxygen species (ROS) $(104,105)$.

Lycopene is considered to be a chemopreventive agent (106), as it maintains the integrity of the vascular barrier, inhibits the expression of cell adhesion molecules and leukocytes, and inhibits EC migration by blocking the expression of NF-кB, CD14 and TLR4, and TNF- $\alpha$ production (107). In addition to decreased levels of malondialdehyde, programmed cell death prevents apoptosis by attenuating the expression of p53 and caspase-3 in ECs treated with $\mathrm{H}_{2} \mathrm{O}_{2}$ (108).

Newly discovered mechanisms include: the reduction of endothelial injury, control of lipid metabolism during the synthesis of cholesterol and oxysterol toxic activity and reduction of the inflammatory response through changes in cytokine production $(109,110)$. While it is known that the consumption of tomato products is associated with a significant increase in plasma levels of lycopene, this has no substantial effect on endothelial function (111). Studies have also found that there are other potent bioactive compounds in tomatoes, such as flavonoids, whose nanomolar concentrations protect the cofactor tetrahydrobiopterin from peroxynitrite radicals and maintain the action of endothelial nitric oxide synthase (eNOS) (112). The inhibition of arginase enzyme and of NADPH oxidase combined with $\mathrm{O}_{2}$, which causes a positive NO balance in the EC (113) and prevents apoptosis through p53, has also been shown to inhibit the synthesis of endothelian-1 (ET-1) (114). Its immediate anti-apoptotic function is to block the JNK and p38 MAPK signaling pathways, and its resistance to LDL oxidation through ROS takes place through action on the JAK2/STAT3 pathways (115).

To further understand the endothelial protective effects of bioactive compounds, such as those mentioned above, or those of other bioactive compounds that may be present in the tomato, future studies should focus on the three most important properties of the endothelium: i) markers of vascular tone control, i.e., concentrations of asymmetric dimethylarginine (ADMA), NO, eNOS and ET-1; ii) markers of the regulation of hemostasis, i.e., concentrations of prostacyclin, plasminogen activator inhibitor-1 (PAI-1) and tissue plasminogen activator (tPA); and iii) markers of the immune system, i.e., the presence of sICAM-1, sE-selectin, sVCAM-1, IL-6, TNF- $\alpha$ and CRP high-sensitivity (hsCRP).

\section{Conclusion}

The initiation and development of CVD is marked by platelet-endothelial interaction. This interaction promotes the expression of adhesion molecules on the endothelium and the recruitment of inflammatory cells, and stimulates the activation of circulating platelets. In the prevention of CVD, the consumption of $\mathrm{F} \& \mathrm{~V}$ is crucial. At the level of primary prevention, tomato consumption promotes cardiovascular health through its role in platelet anti-aggregation activity and its endotheliumprotective effects. Platelet anti-aggregation activity is regulated by one or more bioactive compounds that act on ADP and collagen receptors. Further research is required in the identification of mechanisms of action of bioactive compounds. In the endothelium, carotenoids and polyphenols act mainly on eNOS and NAPDH-oxidase in order to control the levels of NO and to ensure a reduction in the inflammatory response.

\section{References}

1. World Health Organization. Informe sobre la salud en el mundo. Technical Report. WHO, Geneva, Switzerland, 2002.

2. Jackson CF and Wenger NK: Cardiovascular disease in the elderly. Rev Esp Cardiol 64: 697-712, 2011.

3. Palomo I, Toro C and Alarcón M: The role of platelets in the pathophysiology of atherosclerosis (Review). Mol Med Rep 1: 179-184, 2008.

4. Palomo I, Alarcón M, Moore-Carrasco R and Argilés J: Hemostasis alterations in metabolic syndrome (Review). Int $\mathrm{J}$ Mol Med 18: 969-974, 2006.

5. Palomo I, Torres G, Alarcon M, Maragaño P, Leiva E and Mujica V: Alta prevalencia de factores de riesgo cardiovascular clásicos en una población de estudiantes universitarios de la región centro-sur de Chile. Rev Esp Cardiol 59: 1099-1105, 2006.

6. Palomo I, Icaza G, Mujica V, et al: Prevalencia de factores de riesgo cardiovascular clásicos en población adulta de Talca, Chile, 2005. Rev Med Chile 135: 904-912, 2007.

7. Lubos E, Handy D and Loscalzo J: Role of oxidative stress and nitric oxide in atherothrombosis. Front Biosci 13: 5323-5344, 2009.

8. Badimón L, Vilahur G and Padró T: Lipoproteínas, plaquetas y aterotrombosis. Rev Esp Cardiol 62: 1161-1178, 2009.

9. Roldán I: Nuevos antiagregantes en el síndrome coronario agudo. El futuro es hoy. Rev Esp Cardiol Suppl 10: 12D-22D, 2010.

10. Santos M, Aranda E, Vallés J and Palomo I: Hemostasia primaria. In: Hematología: Fisiopatología y Diagnóstico. Palomo I, Pereira J and Palma J (eds). Editorial Universidad de Talca, Talca, pp459-492, 2005.

11. Zhang J, Blackmore PF, Hargrave BY, Xiao S, Beebe SJ and Schoenbach KH: Nanosecond pulse electric field (nanopulse): a novel non-ligand agonist for platelet activation. Arch Biochem Biophys 471: 240-248, 2008. 
12. Panes O, Matus V, Sáez CG, Quiroga T, Pereira J and Mezzano D Human platelets synthesize and express functional tissue factor. Blood 109: 5242-5250, 2007.

13. Aukrust $\mathrm{P}$, Halvorsen $\mathrm{B}$, Ueland $\mathrm{T}$, et al: Activated platelets and atherosclerosis. Expert Rev Cardiovasc Ther 8: 1297-1307, 2010.

14. Dauchet L, Amouyel P, Hercberg S and Dallongeville J: Fruit and vegetable consumption and risk of coronary heart disease: a meta-analysis of cohort studies. J Nutr 136: 2588-2593, 2006.

15. Koleckar V, Brojerova E, Rehakova Z, et al: In vitro antiplatelet activity of flavonoids from Luzea carthamoides. Drug Chem Toxicol 31: 27-35, 2008.

16. Khan AN, Fatima I, Khaliq UA, Malik A, Miana GA, Qureshi ZU and Rasheed H: Potent anti-platelet constituents from Centaurea iberica. Molecules 16: 2053-2064, 2011.

17. Palomo I, Moore-Carrasco R, Carrasco G, Villalobos P and Guzmán L: El consumo de tomates previene el desarrollo de enfermedades cardiovasculares y cáncer: antecedentes epidemiológicos y mecanismos de acción. Idesia 28: 121-129, 2010.

18. Silverstein R: Inflammation, atherosclerosis, and arterial thrombosis: role of the scavenger receptor CD36. Cleve Clin J Med 76: S27-S30, 2009.

19. Nesbitt WS, Westein E, Tovar-Lopez FJ, et al: A shear gradientdependent platelet aggregation mechanism drives thrombus formation. Nat Med 15: 665-673, 2009.

20. Lindemann S, Kramer B, Seizer P and Gawaz M: Platelets, inflammation and atherosclerosis. J Thromb Haemost 5: 203-211, 2007.

21. Cimmino G, D'Amico C, Vaccaro V, D'Anna M and Golino P: The missing link between atherosclerosis, inflammation and thrombosis: is it tissue factor? Expert Rev Cardiovasc Ther 9: 517-523, 2011.

22. Verhamme $\mathrm{P}$ and Hoylaerts $\mathrm{M}$ : The pivotal role of the endothelium in haemostasis and thrombosis. Acta Clinica Belgica 61: 213-219, 2006.

23. Rau JC, Beaulieu LM, Huntington JA and Church FC: Serpins in thrombosis, hemostasis and fibrinolysis. J Thromb Haemost 5 102-115, 2007.

24. Van Gils J, Zwaginga J and Hordijk P: Molecular and functional interactions among monocytes, platelets, and endothelial cells and their relevance for cardiovascular diseases. J Leukoc Biol 85 195-204, 2009.

25. Palomo I, Torres C, Moore-Carrasco R, Alarcón M and Maragaño P: Platelet anti-aggregants: mechanisms of action and use-associated risks. Vitae 16: 133-143, 2009.

26. Schober A: Chemokines in vascular dysfunction and remodeling. Arterioscler Thromb Vasc Biol 28: 1950-1959, 2008.

27. Badimón JJ, Santos-Gallego C, Torres F, Castillo J and Kaski J: Nuevas herramientas en la estratificación del riesgo cardiovascular. Rev Esp Cardiol Suppl 11(B): 21-28, 2011.

28. Lievens D, Zernecke A, Seijkens T, et al: Platelet CD40L mediates thrombotic and inflammatory processes in atherosclerosis. Blood 116: 4317-4327, 2010.

29. Martín M, Rodríguez I, Palacín M and Coto E: Polimorfismos de metaloproteasas y válvula aórtica bicúspide. Rev Esp Cardiol 63: $1382-1389,2010$

30. Lievens D, Eijgelaar WJ, Biessen EA, Daemen MJ and Lutgens E: The multi-functionality of CD40L and its receptor CD40 in atherosclerosis. Thromb Haemost 102: 206-214, 2009.

31. Giannini S, Falcinelli E, Bury L, Guglielmini G, Rossi R, Momi S and Gresele P: Interaction with damaged vessel wall in vivo in humans induces platelets to express CD40L resulting in endothelial activation. No effect of aspirin intake. Am J Physio Heart Circ Physiol 300: 2072-2079, 2011.

32. Gleissner C, Von Hundelshausen P and Ley K: Platelet chemokines in vascular disease. Arterioscler Thromb Vasc Biol 28: 1920-1927, 2008.

33. Totani L and Evangelista V: Platelet-leukocyte interactions in cardiovascular disease and beyond. Arterioscler Thromb Vasc Biol 30: 2357-2361, 2010.

34. Semple J, Italiano J and Freedman J: Platelets and the immune continuum. Nat Rev Immunol 11: 264-274, 2011.

35. Siegel-Axel D and Gawaz M: Platelets and endothelial cells. Semin Thromb Hemost 33: 128-135, 2007.

36. Von Hundelshausen P and Weber C: Platelets as immune cells: bridging inflammation and cardiovascular disease. Circ Res 100: 27-40, 2007.

37. Badimon L, Storey R and Vilahur G: Update on lipids, inflammation and atherothrombosis. Thromb Haemost 105: S34-S42, 2011.
38. Zineh I, Beitelshees AL, Welder GJ, et al: Epithelial neutrophilactivating peptide (ENA-78), acute coronary syndrome prognosis, and modulatory effect of statins. PLoS One 3: 1-9, 2008.

39. Zernecke A, Shagdarsuren E and Weber C: Chemokines in atherosclerosis. Arterioscler Thromb Vasc Biol 28: 1897-1908, 2008.

40. An G, Wang H, Tang R, et al: P-Selectin glycoprotein ligand-1 is highly expressed on Ly-6Chi monocytes and a major determinant for Ly-6Chi monocyte recruitment to sites of atherosclerosis in mice. Circulation 117: 3227-3237, 2008.

41. Cha BY, Shi WL, Yonezawa T, Teruya T, Nagai K and Woo JT: An inhibitory effect of chrysoeriol on platelet-derived growth factor (PDGF)-induced proliferation and PDGF receptor signaling in human aortic smooth muscle cells. J Pharmacol Sci 110: 105-110, 2009.

42. Vestweber D, Broermann A and Schulte D: Control of endothelial barrier function by regulating vascular endothelial-cadherin. Curr Opin Hematol 17: 230-236, 2010.

43. Komarova Y and Malik A: Regulation of endothelial permeability via paracellular and transcellular transport pathways. Annu Rev Physiol 72: 463-493, 2010.

44. Rojas A and Morales-Segura M: Nitric oxide, an iceberg in cardiovascular physiology: far beyond vessel tone control. Arch Med Res 35: 1-11, 2004.

45. Jennings L: Mechanisms of platelet activation: need for new strategies to protect against platelet-mediated atherothrombosis. Thromb Haemost 102: 248-257, 2009.

46. Badimon L and Martínez-González J: Disfunción endotelial. Rev Esp Cardiol Suppl 6: 21A-30A, 2006.

47. Badimon L, Martinez-Gonzalez J, Llorente-Cortes V, Rodriguez $\mathrm{C}$ and Padro T: Cell biology and lipoproteins in atherosclerosis. Curr Mol Med 6: 439-456, 2006.

48. Deanfield J, Halcox J and Rabelink T: Endothelial function and dysfunction: testing and clinical relevance. Circulation 115: 1285-1295, 2007

49. Martinez-Gonzalez $\mathrm{J}$ and Badimon L: Influence of statin use on endothelial function: from bench to clinics. Curr Pharm Des 13: 1771-1786, 2007.

50. Palomo I, Moore-Carrasco R, Alarcon M, Rojas A, Espana F, Andres V and Gonzalez-Navarro H: Pathophysiology of the proatherothrombotic state in the metabolic syndrome. Front Biosci 2: 194-208, 2010.

51. Matsumoto T, Kobayashi T and Kamata K: Role of lysophosphatidylcholine (LPC) in atherosclerosis. Curr Med Chem 14: 3209-3220, 2007.

52. Erdogan A, Schaefer MB, Kuhlmann CR, et al: Activation of $\mathrm{Ca}^{2+}$ activated potassium channels is involved in lysophosphatidylcholine-induced monocyte adhesion to endothelial cells. Atherosclerosis 190: 100-105, 2007.

53. Zou Y, Kim CH, Chung JH, et al: Upregulation of endothelial adhesion molecules by lysophosphatidylcholine. Involvement of G protein-coupled receptor GPR4. FEBS J 274: 2573-2584, 2007.

54. Kim EA, Kim JA, Park MH, Jung SC, Suh SH, Pang MG and Kim YJ: Lysophosphatidylcholine induces endothelial cell injury by nitric oxide production through oxidative stress. J Matern Fetal Neonatal Med 22: 325-331, 2009.

55. Barbaux S, Poirier O, Pincet F, Hermand P, Tiret L and Deterre P: The adhesion mediated by the P-selectin P-selectin glycoprotein ligand-1 (PSGL-1) couple is stronger for shorter PSGL-1 variants. J Leukoc Biol 87: 727-734, 2010.

56. Ruggeri $Z$ and Mendolicchio L: Adhesion mechanisms in platelet function. Circ Res 100: 1673-1685, 2007.

57. Lu D, Scully M, Kakkar V and Lu X: ADAM-15 disintegrin-like domain structure and function. Toxins 2: 2411-2427, 2010.

58. Charrier-Hisamuddin L, Laboisse C and Merlin D: ADAM-15: a metalloprotease that mediates inflammation. FASEB J 22: 641-653, 2008

59. Badimon L and Vilahur G: Platelets, arterial thrombosis and cerebral ischemia. Cerebrovasc Dis 24: 30-39, 2007.

60. World Health Organization: Joint WHO/FAO Expert Consultation on Diet, Nutrition, and the Prevention of Chronic Diseases. WHO, Geneva, Switzerland, 2003.

61. He FJ, Nowson CA, Lucas M and MacGregor GA: Increased consumption of fruit and vegetables is related to a reduced risk of coronary heart disease: meta-analysis of cohort studies. J Hum Hypertens 21: 717-728, 2007.

62. Iqbal R, Anand S, Ounpuu S, et al: Dietary patterns and the risk of acute myocardial infarction in 52 countries: results of the INTERHEART study. Circulation 118: 1929-1937, 2008. 
63. Carlsen MH, Halvorsen BL, Holte K, et al: The total antioxidant content of more than 3100 foods, beverages, spices, herbs and supplements used worldwide. Nutr J 9: 1-11, 2010.

64. Lako J, Trenerry V, Wahlqvist M, Wattanapenpaiboon N, Sotheeswaran S and Premier R: Phytochemical flavonols, carotenoids and the antioxidant properties of a wide selection of Fijian fruit, vegetables and other readily available foods. Food Chem 101: 1727-1741, 2007.

65. Badimon L, Vilahur G and Padro T: Nutraceuticals and atherosclerosis: human trials. Cardiovasc Ther 28: 202-215, 2010

66. Badimon L and Vilahur G: Enfermedad aterotrombótica coronaria: avances en el tratamiento antiplaquetario. Rev Esp Cardiol 61: 501-513, 2008.

67. Palomo I, Gutiérrez M, Astudillo L, et al: Efecto antioxidante de frutas y hortalizas de la zona central de Chile. Rev Chil Nutr 36 152-158, 2009

68. Dauchet L, Péneau S, Bertrais S, et al: Relationships between different types of fruit and vegetable consumption and serum concentrations of antioxidant vitamins. Br J Nutr 100: 633-641, 2008.

69. Palomo I, Yuri J, Moore-Carrasco R, Quilodrán A and Neira A: El consumo de manzanas contribuye a prevenir el desarrollo de enfermedades cardiovasculares y cáncer: antecedentes epidemiológicos y mecanismos de acción. Rev Chil Nutr 37: 377-385, 2010.

70. Pierre S, Crosbie L and Duttaroy A: Inhibitory effect of aqueous extracts of some herbs on human platelet aggregation in vitro. Platelets 16: 469-473, 2005.

71. Torres-Urrutia C, Guzmán L, Schmeda-Hirschmann G, et al: Antiplatelet, anticoagulant, and fibrinolytic activity in vitro of extracts from selected fruits and vegetables. Blood Coagul Fibrinolysis 22: 197-205, 2011.

72. Nuez F: El cultivo del tomate. Editorial Mundi-Prensa, Barcelona, pp16-20, 1995.

73. Mekhfi H, Gadi D, Bnouham M, Ziyyat A, Legssyer A and Aziz M: Effect of argan oil on platelet aggregation and bleeding time: a beneficial nutritional property. J Complement Integr Med 5: 1-18, 2008

74. Palomo I, Fuentes E, Carrasco G, González D and Moore-Carrasco R: Actividad antioxidante, hipolipemiante y antiplaquetaria del tomate (Solanum lycopersicum L.), y el efecto de su procesamiento y almacenaje. Rev Chil Nutr 37: 524-533, 2010.

75. Dutta-Roy A, Crosbie L and Gordon M: Effects of tomato extract on human platelet aggregation in vitro. Platelets 12: 218-227, 2001.

76. Lazarus S, Dutta-Roy A and Garg M: Aqueous tomato extract inhibits platelet aggregation. Asia Pac J Clin Nutr 11 (Suppl): S240, 2002.

77. Yamamoto J, Taka T, Yamada K, et al: Tomatoes have natura anti-thrombotic effects. Br J Nutr 90: 1031-1038, 2003.

78. Fuentes E, Astudillo L, Gutiérrez M, et al: Fractions of aqueous and methanolic extracts from tomato (Solanum lycopersicum L.) present platelet antiaggregant activity. Blood Coagul Fibrinolysis 23: 109-117, 2012.

79. Lazarus S and Garg M: Tomato extract inhibits human platelet aggregation in vitro without increasing basal cAMP levels. Int J Food Sci Nutr 55: 249-256, 2004.

80. O'Kennedy N, Crosbie L, van Lieshout M, Broom JI, Webb DJ and Duttaroy AK: Effects of antiplatelet components of tomato extract on platelet function in vitro and ex vivo: a time-course cannulation study in healthy humans. Am J Clin Nutr 84 570-579, 2006

81. O'Kennedy N, Crosbie L, Whelan S, et al: Effects of tomato extract on platelet function: a double-blinded crossover study in healthy humans. Am J Clin Nutr 84: 561-569, 2006.

82. Provesi J, Odebrecht C and Amante E: Changes in carotenoids during processing and storage of pumpkin puree. Food Chem 128: 195-202, 2011.

83. Nguyen ML and Schwartz SJ: Lycopene: chemical and biological properties. Food Technol 58: 38-44, 1999.

84. Shi J and Le M: Lycopene in tomatoes: chemical and physical properties affected by food processing. Crit Rev Biotechnol 20 293-334, 2000

85. Agrawal H, Kaul N, Paradkar AR and Mahadik KR: Stability indicating HPTLC determination of clopidogrel bisulphate as bulk drug and in pharmaceutical dosage form. Talanta 61: $581-589,2003$

86. Lazarus S, Bowen K and Garg M: Tomato juice and platelet aggregation in type 2 diabetes. JAMA 292: 805-806, 2004.

87. Murphy K, Chronopoulos A, Singh I, et al: Dietary flavanols and procyanidin oligomers from cocoa (Theobroma cacao) inhibit platelet function. Am J Clin Nutr 77: 1466-1473, 2003.
88. Born G and Cross M: The aggregation of blood platelets. J Physiol 168: 178-195, 1963.

89. Unsworth AJ, Smith H, Gissen P, Watson SP and Pears CJ. Submaximal inhibition of protein kinase c restores ADP-induced dense granule secretion in platelets in the presence of $\mathrm{Ca}^{2+} . \mathrm{J}$ Biol Chem 286: 21073-21082, 2011.

90. Kim S, Jin J and Kunapuli S: Akt activation in platelets depends on Gi signaling pathways. J Biol Chem 279: 4186-4195, 2004.

91. Guidetti GF, Bernardi B, Consonni A, Rizzo P, Gruppi C, Balduini $\mathrm{C}$ and Torti $\mathrm{M}$ : Integrin $\alpha 2 \beta 1$ induces phosphorylation-dependent and phosphorylation-independent activation of phospholipase $C \gamma 2$ in platelets: role of Src kinase and Rac GTPase. J Thromb Haemost 7: 1200-1206, 2009.

92.Kim SD, Lee IK, Lee WM, et al: The mechanism of antiplatelet activity of davallialactone: involvement of intracellular calcium ions, extracellular signal-regulated kinase 2 and p38 mitogen-activated protein kinase. Eur J Pharmacol 584: 361-367, 2008

93. Liu FC, Liao CH, Chang YW, Liou JT and Day YJ: A new insight of anti-platelet effects of sirtinol in platelet aggregation via cyclic AMP phosphodiesterase. Biochem Pharmacol 77: 1364-1373, 2009.

94. Ferreiro J, Gómez-Hospital J, Angiolillo D and Cequier A: Los nuevos antagonistas del receptor P2Y12 pueden reemplazar a los inhibidores de la glucoproteína IIb/IIIa? Rev Esp Cardiol Suppl 11(A): 14-19, 2011.

95. Angiolillo DJ and Ferreiro JL: Platelet adenosine diphosphate P2Y12 receptor antagonism: benefits and limitations of current treatment strategies and future directions. Rev Esp Cardiol 63: 60-76, 2010

96. Olas B, Wachowicz B, Tomczak A, Erler J, Stochmal A and Oleszek W: Comparative anti-platelet and antioxidant properties of polyphenol-rich extracts from: berries of Aronia melanocarpa, seeds of grape and bark of Yucca schidigera in vitro. Platelets 19: 70-77, 2008

97. Spiel AO, Gilbert JC and Jilma B: Von Willebrand factor in cardiovascular disease: focus on acute coronary syndromes. Circulation 117: 1449-1459, 2008

98. Fernández-Ortiz A, Núñez-Gil I, Ruiz-Mateos B and Ibáñez B: Propiedades de los diferentes inhibidores de la glucoproteína IIb/IIIa: se puede aceptar el efecto de clase? Rev Esp Cardiol Supl 11: 3-7, 2011.

99. Paran E, Novack V, Engelhard YN and Hazan-Halevy I: The effects of natural antioxidants from tomato extract in treated but uncontrolled hypertensive patients. Cardiovasc Drugs Ther 23: $145-151,2009$.

100. Silaste ML, Alfthan G, Aro A, Kesäniemi YA and Hörkkö S: Tomato juice decreases LDL cholesterol levels and increases LDL resistance to oxidation. Br J Nutr 98: 1251-1258, 2007.

101. Kim JY, Paik JK, Kim OY, Park HW, Lee JH, Jang Y and Lee JH: Effects of lycopene supplementation on oxidative stress and markers of endothelial function in healthy men. Atherosclerosis 215: 189-195, 2011

102.Hung CF, Huang TF, Chen BH, Shieh JM, Wu PH and Wu WB: Lycopene inhibits TNF-alpha-induced endothelial ICAM-1 expression and monocyte-endothelial adhesion. Eur J Pharmacol 586: 275-282, 2008.

103. Cavallini C, Trettene M, Degan M, Delva P, Molesini B, Minuz P and Pandolfini T: Anti-angiogenic effects of two cystine-knot miniproteins from tomato fruit. Br J Pharmacol 162: 1261-1273, 2011.

104. Lee D, Grantham R, Mannion J and Trachte A: Carotenoids enhance phosphorylation of Akt and suppress tissue factor activity in human endothelial cells. J Nutr Biochem 17: 780-786, 2006.

105. Palozza P, Simone R, Catalano A, et al: Lycopene prevents 7-ketocholesterol-induced oxidative stress, cell cycle arrest and apoptosis in human macrophages. J Nutr Biochem 21: 34-46, 2010.

106. Santangelo C, Varì R, Scazzocchio B, Di Benedetto R, Filesi C and Masella R: Polyphenols, intracellular signalling and inflammation. Ann Ist Super Sanita 43: 394-405, 2007.

107. Wood L and Gibson P: Dietary factors lead to innate immune activation in asthma. Pharmacol Ther 123: 37-53, 2009.

108. Tang X, Yang X, Peng Y, Peng Y and Lin J: Protective effects of lycopene against $\mathrm{H}_{2} \mathrm{O}_{2}$-induced oxidative injury and apoptosis in human endothelial cells. Cardiovasc Drugs Ther 23: 439-448, 2009.

109. Palozza P, Parrone N, Simone R and Catalano A: Lycopene in atherosclerosis prevention: an integrated scheme of the potential mechanisms of action from cell culture studies. Arch Biochem Biophys 504: 26-33, 2010. 
110. Simone R, Russo M, Catalano A, Monego G, Froehlich K, Boehm V and Palozza P: Lycopene inhibits Nf- $\kappa \mathrm{B}$-mediated IL-8 expression and changes Redox and PPAR $\gamma$ signalling in cigarette smoke-stimulated macrophages. PLoS One 6: 1-11, 2011.

111. Stangl V, Kuhn C, Hentschel S, et al: Lack of effects of tomato products on endothelial function in human subjects: results of a randomised, placebo-controlled cross-over study. Br J Nutr 105: 263-267, 2011

112. McCarty M: Scavenging of peroxynitrite-derived radicals by flavonoids may support endothelial NO synthase activity, contributing to the vascular protection associated with high fruit and vegetable intakes. Med Hypotheses 70: 170-181, 2008.
113. Weseler A and Bast A: Oxidative stress and vascular function: implications for pharmacologic treatments. Curr Hypertens Rep 12: 154-161, 2010.

114. Duran X, Vilahur G and Badimon L: Exogenous in vivo NO-donor treatment preserves p53 levels and protects vascular cells from apoptosis. Atherosclerosis 205: 101-106, 2009.

115. Choi J, Choi Y, Shin S, et al: Dietary flavonoids differentially reduce oxidized LDL-induced apoptosis in human endothelial cells: role of MAPK- and JAK/STAT-signaling. J Nutr 138: 983-990, 2008. 